\title{
Mapeo de cangahuas mediante teledetección en el Ecuador
}

\section{Mapping cangahua in Ecuador using remote sensing}

\author{
Wilmer Jiménez ${ }^{1}$, Verónica Loayza ${ }^{1}$, Eric Metzler $^{1}$ \\ $\bigotimes$ : wilmerjm@gmx.com
}

\begin{abstract}
1 Dirección de Investigación y Generación de Datos Multisectoriales, Coordinación General del Sistema de Información Nacional, Ministerio de Agricultura y Ganadería. Av. Amazonas y Av. Eloy Alfaro. CP 170516. Quito, Ecuador.
\end{abstract}

\begin{abstract}
Resumen
Los paisajes de la Sierra de Ecuador están estrechamente ligados a las actividades volcánicas suscitadas hace miles de años. Durante estos eventos se expulsaron materiales volcánicos y cenizas formando lodos volcánicos que se difundieron y endurecieron en las zonas de influencia de los volcanes. Luego el material fue cubierto por ceniza volcánica que desarrolló el suelo superficial. Los habitantes locales llaman a este material endurecido "cangahua", que en idioma quichua quiere decir "tierra dura". El mal manejo del suelo provocado por la presión sobre la tierra ha generado un proceso erosivo que ha arrastrado el suelo superficial y descubierto la cangahua interior de baja calidad agrícola. En la actualidad, el desarrollo de la agricultura en las zonas de cangahua es muy difícil y los agricultores tienden a abandonar estas tierras empobrecidas. El objetivo de este estudio fue generar el mapa de cangahuas superficiales del Ecuador a escala 1:25.000 para puntualizar la localización de la cangahua aflorante (expuesta en la superficie) y la cangahua en profundidad hasta $60 \mathrm{~cm}$ (cubierta por suelo u otro material). Se analizaron los factores decisivos para la afloración de cangahua como sistema volcánico, altitud, relieve, patrones de erosión y deposición, suelos y cobertura visible. Estos factores permitieron establecer la dinámica de comportamiento y presencia de este material en el paisaje mediante ortofotografía e imágenes satelitales de alta resolución espacial que se encuentran disponibles en las plataformas de Google Earth Pro y ArcGIS Earth, entre ellas DigitalGlobe y CNES/Airbus. El estudio se apoyó con información levantada en campo mediante GPS e información secundaria como mapas de suelos, geopedología, Modelo Digital del Terreno, curvas de nivel e imágenes Google Street View. Se demostró que, a nivel nacional, el área total de cangahuas superficiales es de 181.487 ha, de las cuales 13.162 ha corresponden a cangahua aflorante y 168.325 ha a cangahua en profundidad de hasta $60 \mathrm{~cm}$.
\end{abstract}

Palabras clave: suelo, toba volcánica, erosión, imágenes satelitales, sistemas de información geográfica.

\begin{abstract}
Thousands of years ago, certain section of the Ecuadorian sierra experienced strong volcanic activity. During these volcanic events, igneous material and ash were ejected, forming a zone of volcanic mud that fused and hardened. Afterwards, this material was covered by volcanic ash that further affected the surface soil. Local residents call this hardened material cangahua, which in Kichwa means "hard land". Bad soil management practices promoted by land pressure have unleashed erosive processes that have removed the surface soil and exposed the lower cangahua layer. By its nature, cangahua is a poor agricultural substrate. Today, farming in the cangahua region is very difficult, and farmers often abandon their impoverished lands. The goal of this study was to generate a 1:25.000 scale map of the cangahua zones in Ecuador. This map helped to pinpoint the location of both exposed cangahua and cangahua layers up to $60 \mathrm{~cm}$ deep covered by soils and other materials. The study analyzed the factors that determined cangahua exposure, including volcanic system dynamics, altitude, topography, erosion patterns and deposition, soils and visible cover. The analysis of these factors led to the modelling of cangahua behavior and its role on the landscape. This project relied on orthophotography and high-resolution satellite images from space taken from the Google Earth Pro and ArcGIS Earth applications, including the DigitalGlobe and Airbus Defense and Space's
\end{abstract}


CNES catalogues. It was supported by collecting field data using GPS, and deriving secondary data from soil survey maps, geopedology, digital terrain modeling (DTM), contour line maps and Google Street View images. The study concluded that, at national level, the total area covered by cangahua deposits is of 181.487 ha, of which 13.162 ha are exposed cangahua and 168.325 ha are deposits of cangahua located up to a depth of $60 \mathrm{~cm}$.

Keywords: soil, volcanic limestone, erosion, satellite images, geographic information system.

\section{Introducción}

En amplias áreas de la Sierra de Ecuador es evidente la presencia de un material endurecido originado hace miles de años por erupciones volcánicas. El material se depositó principalmente en forma de coladas de lodo volcánico que luego se endurecieron y fueron cubiertas por ceniza volcánica y/u otros materiales (Vera \& López, 1982). Localmente, este material es conocido como "cangahua", que en idioma quichua significa "tierra dura". En otras áreas del mundo donde ocurrieron eventos similares, la cangahua se conoce con diferentes nombres, denominándose tepetate en México (Peña et al., 1992; Zebrowski et al., 1989), Talpetate en Nicaragua (Prat, 1991), Sillar en Perú (Nimlos et at., 1992), Hardpan y Cangahua en Colombia, Cancahua, Moromoro y Tosca en Chile (Zebrowski, 1997) y Kora y Masa en Japón (Nimlos, 1987). Este material tiene muy bajo contenido de materia orgánica, nitrógeno y fósforo y muy poca actividad microbiana. Además, la cangahua es muy compacta, condición que limita la retención de agua y la penetración y desarrollo de raíces. Por estas razones, en las zonas donde existe cangahua, la actividad agrícola tiene severas limitaciones.

En Ecuador, la cangahua se presenta en la naturaleza en dos formas particulares: material expuesto a la superficie (cangahua aflorante) o material bajo el suelo $u$ otros materiales (cangahua en profundidad). La presencia de cangahua aflorante indica que la capa de suelo que la cubría se ha erosionado haciendo imposible la producción agropecuaria, situación que deriva en una serie de problemas como migración y expansión de la frontera agrícola a ecosistemas frágiles (páramos) en búsqueda de mejores suelos. Por otra parte, diversos estudios realizados en este tipo de material, principalmente en México (Prat et al., 2003; Navarro et al., 1998; Báez et al., 1996; Navarro et al., 1997; Zebrowski et al., 1997; Etchevers et al., 1992) y en Ecuador (Podwojewski et al., 2008; Cangás et al., 1997; Terán, 1997; Trujillo et al., 1997; Quantin et al., 1997; De Noní et al., 1989) han demostrado que es posible rehabilitar este material estéril para convertirlo en suelo vivo y productivo mediante una serie de prácticas de manejo sostenible que se inician con la roturación y un manejo agronómico que permita acumular carbono orgánico e incremente la fertilidad del suelo.

En el país se han conducido diversos estudios que han desarrollado mapas que de una forma $u$ otra han demostrado la intensidad del problema de erosión y de afloración de cangahua en varios contextos. Entre estos se pueden mencionar el mapa de suelos de la Sierra ecuatoriana a escala 1:50.000, mapa de suelos de la Costa ecuatoriana a escala 1:200.000 y mapa de suelos de la Amazonía ecuatoriana a escala 1:250.000 generados por el Ministerio de Agricultura y Ganadería y la Office de la Recherche Scientifique et Technique Outre-Mer de Francia (MAG \& ORSTOM, 1982) y los mapas de información geopedológica cantonal a escala 1:25.000 generada en los proyectos "Generación de Geoinformación para la Gestión del Territorio a Nivel Nacional escala 1:25.000" realizado por el Instituto Espacial Ecuatoriano (IEE), Ministerio de Agricultura, Ganadería, Acuacultura y Pesca (MAGAP) y Secretaría Nacional de Planificación y Desarrollo (SENPLADES) (IEE et al., 2015) y "Levantamiento de Cartografía Temática escala 1:25.000, lote 1 y 2" (MAGAP, 2016).

Además, el estudio realizado por Jiménez et al., (2016) para identificar cangahuas mediante imágenes satelitales RapidEye analizó los tipos de suelos relacionados con la presencia de este material. Los mapas desarrollados, si bien constituyen un aporte referencial importante, contienen información limitada, ya sea por su escala o por falta de información específica sobre la localización y profundidad de las cangahuas y no proporcionan información suficiente para la planificación de la rehabilitación de cangahuas al detalle requerido. Estas limitantes de precisión y exactitud fueron analizadas por Metzler et al., (2016), quienes generaron y validaron un mapa de cangahuas a escala 1:15.000 para la parroquia Tocachi, provincia de Pichincha, encontrando que 
la localización y superficie de las áreas de cangahua identificados son en gran parte distintas a las áreas de cangahuas señaladas en los mapas del estudio anteriormente mencionado.

El principal objetivo del presente estudio fue generar un mapa a nivel nacional que identifique la cangahua aflorante (material expuesto a la superficie) y la cangahua en profundidad (material cubierto por suelo $u$ otros materiales hasta $60 \mathrm{~cm}$ de profundidad) a escala 1:25.000, utilizando productos de sensores remotos como imágenes aéreas ortorrectificadas (ortofotos) e imágenes satelitales de alta resolución espacial e insumos cartográficos disponibles y de libre acceso. El mapa debe proporcionar información detallada para la estimación de superficie de las áreas afectadas por cangahua y un análisis a nivel nacional, provincial y cantonal de los sitios con cangahua que puedan ser roturados y rehabilitados para su conversión en suelo productivo.

\section{Materiales y métodos}

\subsection{Zona de estudio}

El análisis de la información secundaria de los estudios realizados por Jiménez et al., (2016) y Metzler et al., (2016), indica que las cangahuas pueden encontrarse únicamente en las zonas donde existe influencia relativamente cercana a los volcanes pertenecientes principalmente al período Cuaternario, la mayoría ex- tintos o dormidos, y cuya última erupción ocurrió hace más de 10.000 años (Bernard \& Andrade, 2011).

Por otra parte, los estudios realizados por el MAG \& ORSTOM (1982) que analizaron las cangahuas según una topo-clima-secuencia, indican que éstas se encuentran en los regímenes de humedad del suelo usti-arídico, ústico, usti-údico y údico, pero no en el régimen ácuico, razón por la cual, se descartaron del estudio las áreas de influencia de los volcanes de la región amazónica. Por otro lado, los volcanes de las Islas Galápagos no formaron parte del estudio debido a que se excluyeron las áreas protegidas por el Estado ecuatoriano mediante el Sistema Nacional de Áreas Protegidas (SNAP) del Ministerio del Ambiente (MAE, 2015). De esta manera se determinó que la zona de estudio es la descrita en la Figura 1; sin embargo, es necesario indicar que se realizó un barrido a nivel nacional con imágenes satelitales TerraColor de $15 \mathrm{~m}$ de resolución espacial, disponibles en la plataforma de ArcGIS Earth 1.5 (2017), para buscar patrones espaciales similares al de las zonas representativas con cangahuas (Figura 4), y al no encontrar similitud entre los volcanes de la Amazonía y de la Sierra se ratificó que la zona de estudio corresponde a la Sierra Centro y Sierra Norte del país. La investigación se desarrolló en cinco fases: análisis de información secundaria, planificación y levantamiento de información en campo, interpretación de imágenes satelitales y aéreas, validación y edición final y control de calidad.

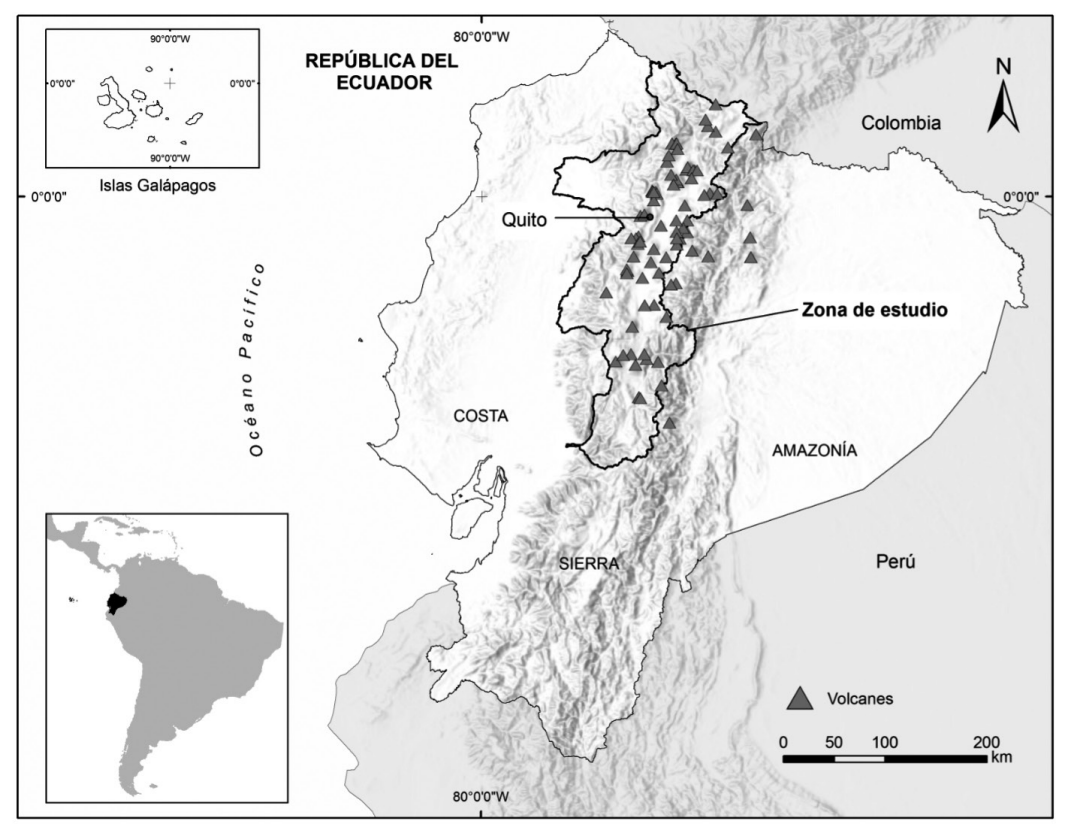

Figura 1. Zona de estudio. 


\subsection{Análisis de información secundaria}

El estudio se inició con un análisis comparativo de la cartografía existente de suelos de la Sierra ecuatoriana a escala 1:50.000 generada por MAG \& ORSTOM (1982) e información geopedológica escala 1:25.000 generada por IEE et al., (2015) y el MAGAP (2016). Se revisó la información sobre la ubicación y profundidad de las cangahuas, consultando memorias técnicas, leyendas, mapas, puntos de campo y respaldos de los puntos de campo disponibles y se identificaron las zonas de conflicto y áreas de consistencia entre los insumos. A partir de este análisis se generó un mapa referencial de las zonas donde las cangahuas fueron encontradas por puntos de campo de otros proyectos o donde la información secundaria de suelos indicaba su posible presencia.

\subsection{Planificación y levantamiento de información en campo}

La ubicación de los puntos de estudio se logró utilizando el criterio preliminar sobre el patrón espacial de las cangahuas superficiales (Figura 4) que visualiza las áreas con imágenes satelitales de alta resolución espacial como DigitalGlobe y CNES/Airbus con resolución entre $61 \mathrm{~cm}$ y $150 \mathrm{~cm}$ disponibles en las plataformas Google Earth Pro 7.3 (2017) y ArcGIS Earth 1.5 (2017) e imágenes aéreas con resolución espacial entre 30 y 50 cm (MAGAP, 2013). Esta parte del estudio, que se desarrolló en dos fases, permitió que se levanten un total 464 puntos georreferenciados (Figura 2) con un Sistema de Posicionamiento Global, con su respectiva ficha de campo y 3.384 fotografías, información que luego fue ingresada en una geodatabase para su posterior análisis mediante un Sistema de Información Geográfica.

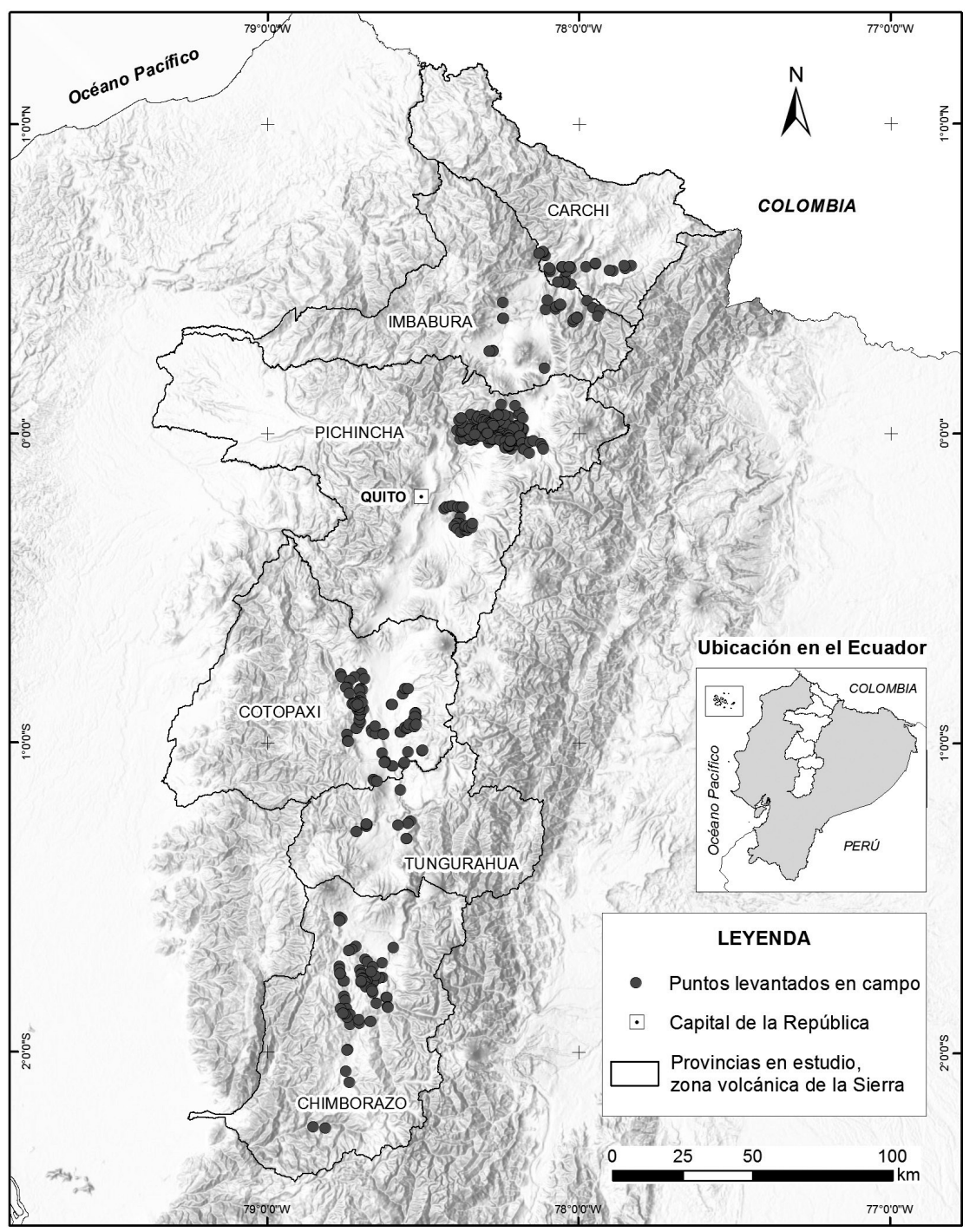

Figura 2. Ubicación de los puntos de estudio levantados en campo. 
****En la primera fase se levantaron 230 puntos en los cantones de Cayambe y Pedro Moncayo en la provincia de Pichincha como zonas piloto para estudiar la dinámica de las cangahuas dentro del paisaje volcánico, de éstos, 68 corresponden a lugares donde se observó afloramientos de cangahua (Figura 3a) y 162 a lugares donde se encontró a la cangahua enterrada o en profundidad mediante minicalicatas $\mathrm{o}$ cajones (Figura 3b). La segunda fase consistió en levantar información en el resto de la zona de estudio que comprende a las provincias de Carchi, Imbabura, Pichincha (excepto Cayambe y Pedro Moncayo), Cotopaxi, Tungurahua y Chimborazo. Se levantaron 234 puntos de observaciones paisajísticas en las zonas más representativas y en las que presentaban mayor incertidumbre.

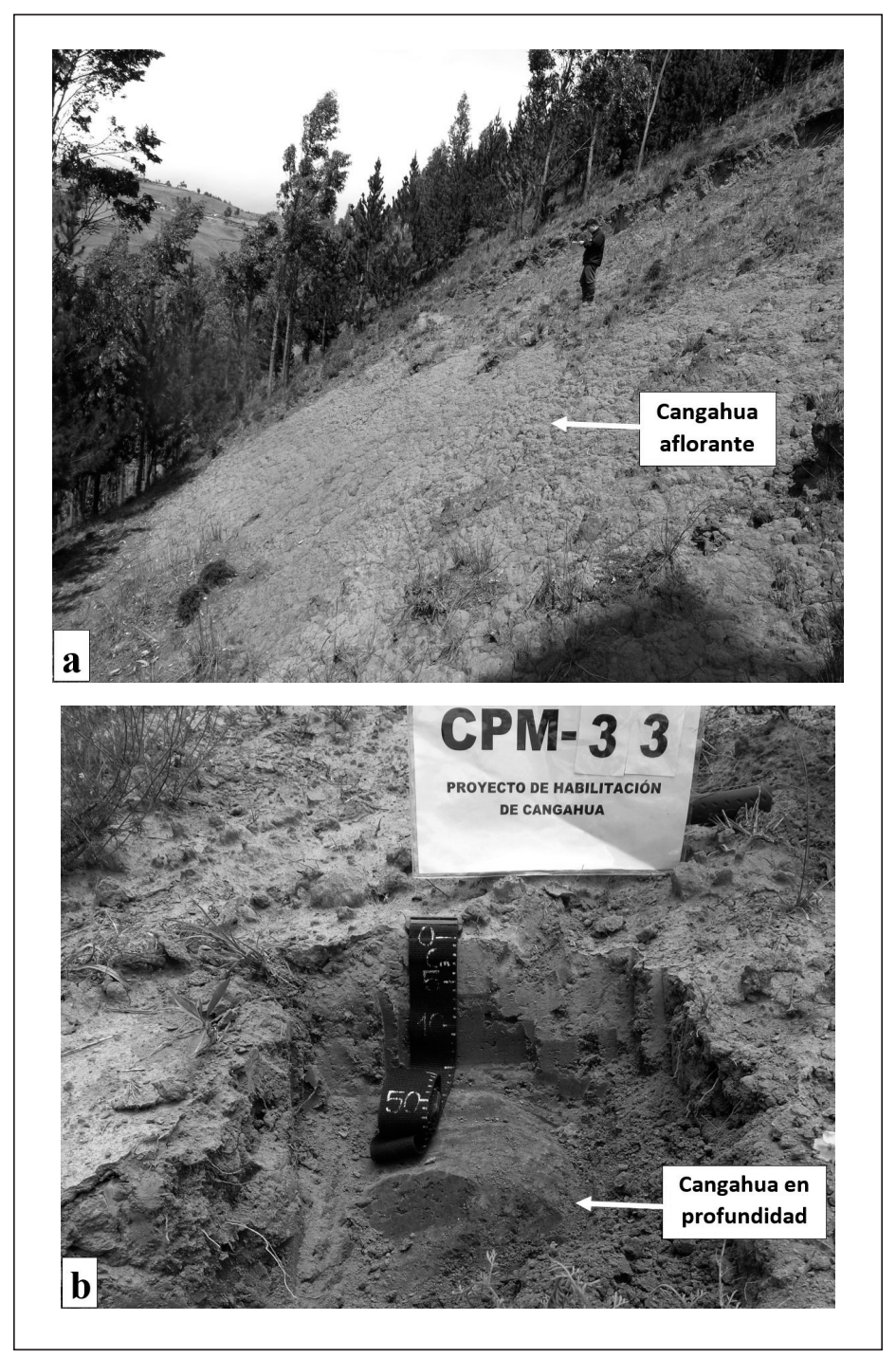

Figura 3. Levantamiento de información en campo. (a) Cangahua aflorante donde se ha perdido totalmente el suelo y la vegetación de cobertura, toma de punto de observación. (b) Cangahua en profundidad cubierta por una delgada capa de suelo encontrada mediante una pequeña excavación (minicalicata o cajón), en el sitio también se observa la presencia de vegetación.

\subsection{Interpretación de imágenes satelitales y aéreas}

Mediante la información levantada en campo, apoyada por el análisis de información secundaria y por los estudios realizados por Jiménez et al.,
(2016) y Metzler et al., (2016), se identificaron espacialmente las zonas con potencial presencia de cangahuas superficiales (Figura 4) utilizando imágenes satelitales de alta resolución espacial disponibles en las plataformas Google Earth Pro 7.3 (2017) y Arc- 
GIS Earth 1.5 (2017) e imágenes aéreas. El mapeo consistió en la interpretación visual de las imágenes satelitales y aéreas donde las cangahuas superficiales convergen con un entorno volcánico, principalmente volcanes cuaternarios que presentan flujos de lodo o depósitos piroclásticos, relieves ondulados y ligeramente ondulados, altitudes menores a los $4.100 \mathrm{~m}$, zonas semi-áridas con dominio de suelo erosionado por viento y agua, escasa cobertura vegetal con nula o limitada presencia de árboles (al menos bosques naturales), sin rasgos de movimientos en masa, continuidad multi-temporal de los afloramientos de cangahuas y aclaramientos de la superficie.

La cangahua aflorante presenta un patrón espacial particular con escasa o nula cobertura vegetal observada mediante ortofotos (Figura 5) e imágenes satelitales de alta resolución espacial disponibles en Google Earth Pro 7.3 (Figura 6) y ArcGIS Earth 1.5. En las mismas plataformas se analizó al relieve en un ambiente tridimensional, factor clave para estu- diar las zonas con flujos de lodo volcánico y caída de ceniza, debido a que en estos lugares se encuentra la cangahua en profundidad. Además, el análisis se apoyó con un Modelo Digital del Terreno (IGM, 2008) y curvas de nivel mediante un software SIG. Adicionalmente, se utilizaron imágenes de Google Street View, disponibles en Google Earth Pro, que sirvieron para analizar el paisaje en zonas donde no fue posible levantar información y para complementar la que se levantó en los lugares donde si existió información. La escala de trabajo fue 1:25.000, indicado para el análisis y planificación a nivel nacional, provincial y cantonal y la Unidad Mínima de Mapeo (UMM) se estableció en 1 ha. La cangahua aflorante con áreas menores a una UMM se encuentra dentro de la categoría de cangahua en profundidad. Con los criterios antes mencionados se extrapoló el análisis al resto de la zona de estudio y se obtuvo un mapa preliminar de cangahuas superficiales.

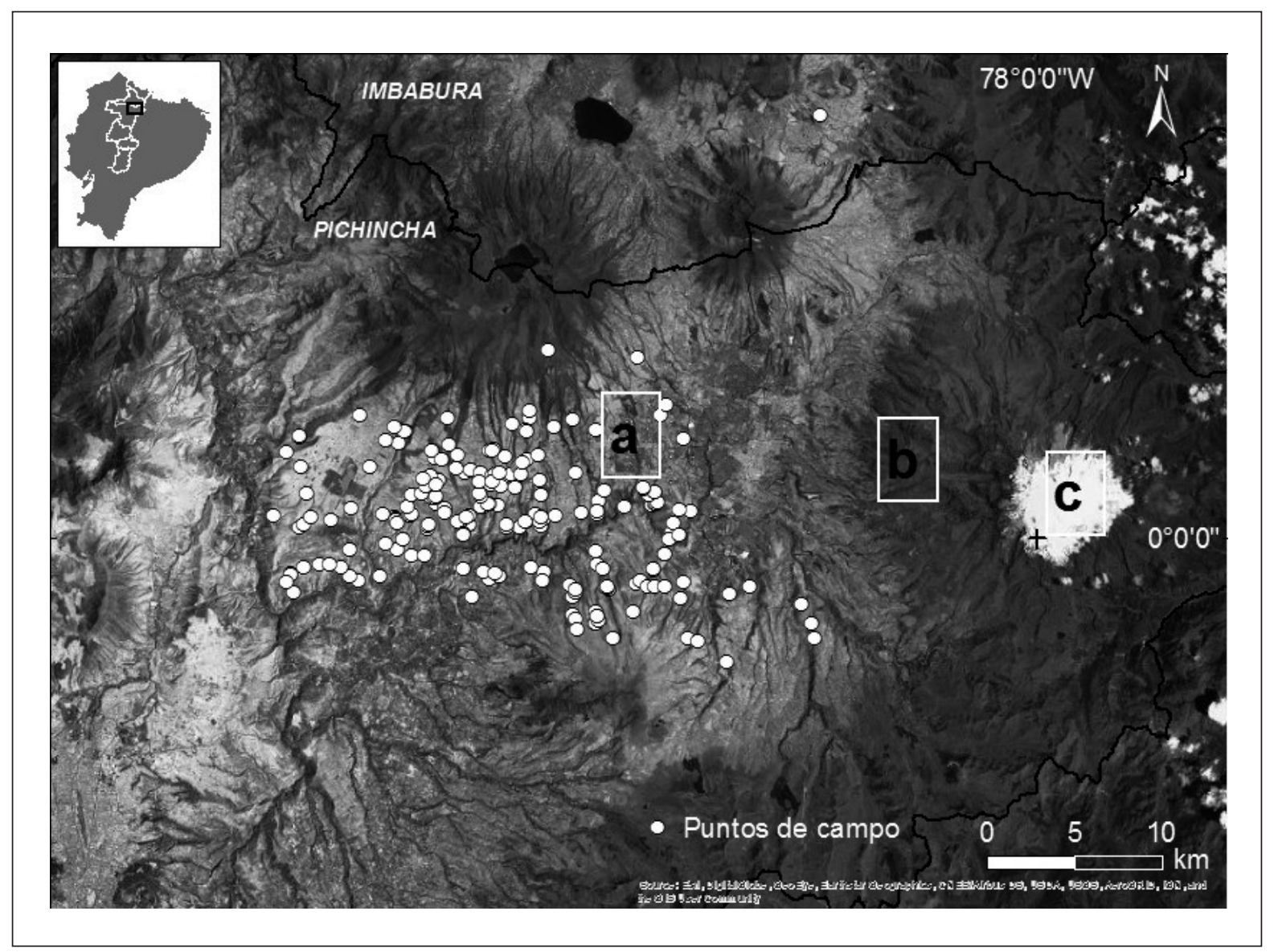

Figura 4. Imagen satelital TerraColor de la zona piloto del levantamiento de información disponible en ArcGIS Earth 1.5. (a) Patrón espacial de las cangahuas superficiales en zonas secas de los piedemontes de los volcanes de la Sierra. (b) Zonas húmedas con poca o nula presencia de cangahuas. (c) Cumbre del volcán Cayambe. 


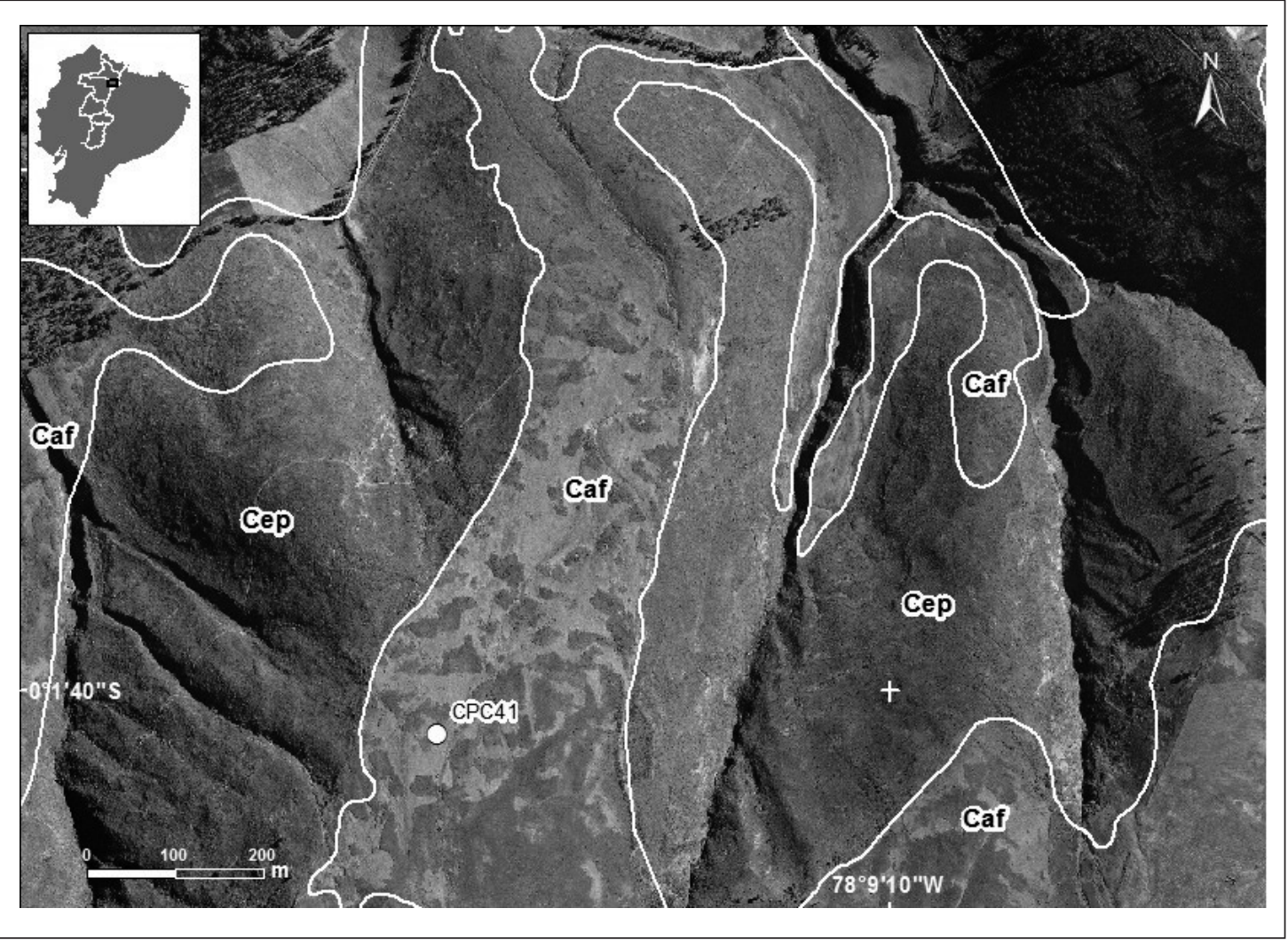

Figura 5. Análisis del patrón espacial de distribución de las cangahuas y mapeo mediante ortofotos apoyado con puntos de campo (CPC41 en la imagen). (Caf) Cangahua aflorante, con escasa o nula cobertura vegetal, ubicada en el piedemonte del volcán Pambamarca, cantón Cayambe, provincia de Pichincha. (Cep) Cangahua en profundidad, cubierta con suelo y vegetación, sin presencia de bosque natural.

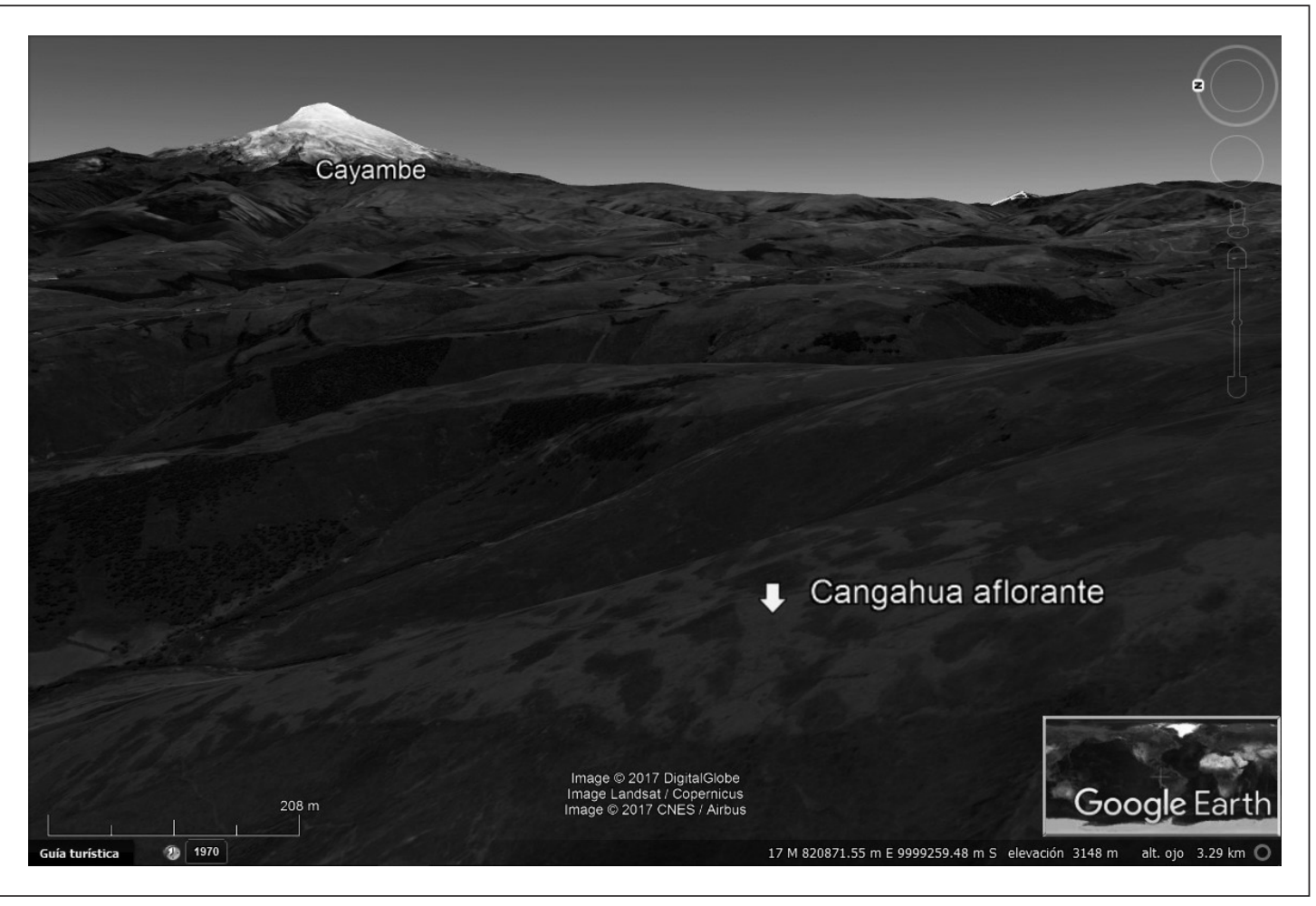

Figura 6. Análisis del patrón espacial y tridimensional de la distribución de las cangahuas mediante imágenes satelitales de alta resolución espacial, entre ellas DigitalGlobe y CNES/Airbus, disponibles en Google Earth Pro 7.3. Volcán Cayambe en el fondo. 


\subsection{Validación y edición final}

La validación se realizó con el apoyo del personal técnico de las Unidades Zonales de Información (UZI) y de las Direcciones Provinciales Agropecuarias (DPA) del Ministerio de Agricultura y Ganadería de cada provincia en estudio, mediante la conformación de Mesas Técnicas. Los técnicos de apoyo recibieron la capacitación necesaria y el mapa preliminar, en formato digital y físico, donde se señalaron las zonas prioritarias y las de mayor incertidumbre. Los informes de validación constaron de observaciones puntuales en cada provincia, con información georreferenciada y fotografías, los cuales fueron esenciales para la edición final.

\section{Resultados}

Debido a la complejidad de la distribución de las cangahuas superficiales y su interrelación con cada paisaje en la Sierra Centro y Norte del país, en este estudio se procedió al mapeó de manera visual, utili- zando imágenes aéreas y satelitales de alta resolución espacial entre 0,3 y 1,5 m. Los resultados encontrados discrepan con los resultados obtenidos por los estudios de Jiménez et al. (2016), Servenay et al. (2000), Servenay (1995) y González et al. (1992) quienes analizaron imágenes satelitales multiespectrales con resolución espacial entre 5 y $30 \mathrm{~m}$, combinando bandas en falso color para delimitar de manera aproximada las zonas con cangahuas superficiales, lo que requirió, más tarde, de una edición visual con insumos de mayor resolución espacial. Como se observa en el mapa de la Figura 7, las cangahuas superficiales localizadas en la zona de estudio corresponden a áreas localizadas en las provincias de Carchi, Imbabura, Pichincha, Cotopaxi, Tungurahua y Chimborazo, asociadas a las vertientes de los volcanes de la Sierra Centro y Norte del país. El estudio determinó que la presencia de cangahuas superficiales en el Ecuador se encuentra estrechamente ligada a la actividad volcánica del período Cuaternario y que su aparición cerca o en la superficie se debe a procesos de erosión.

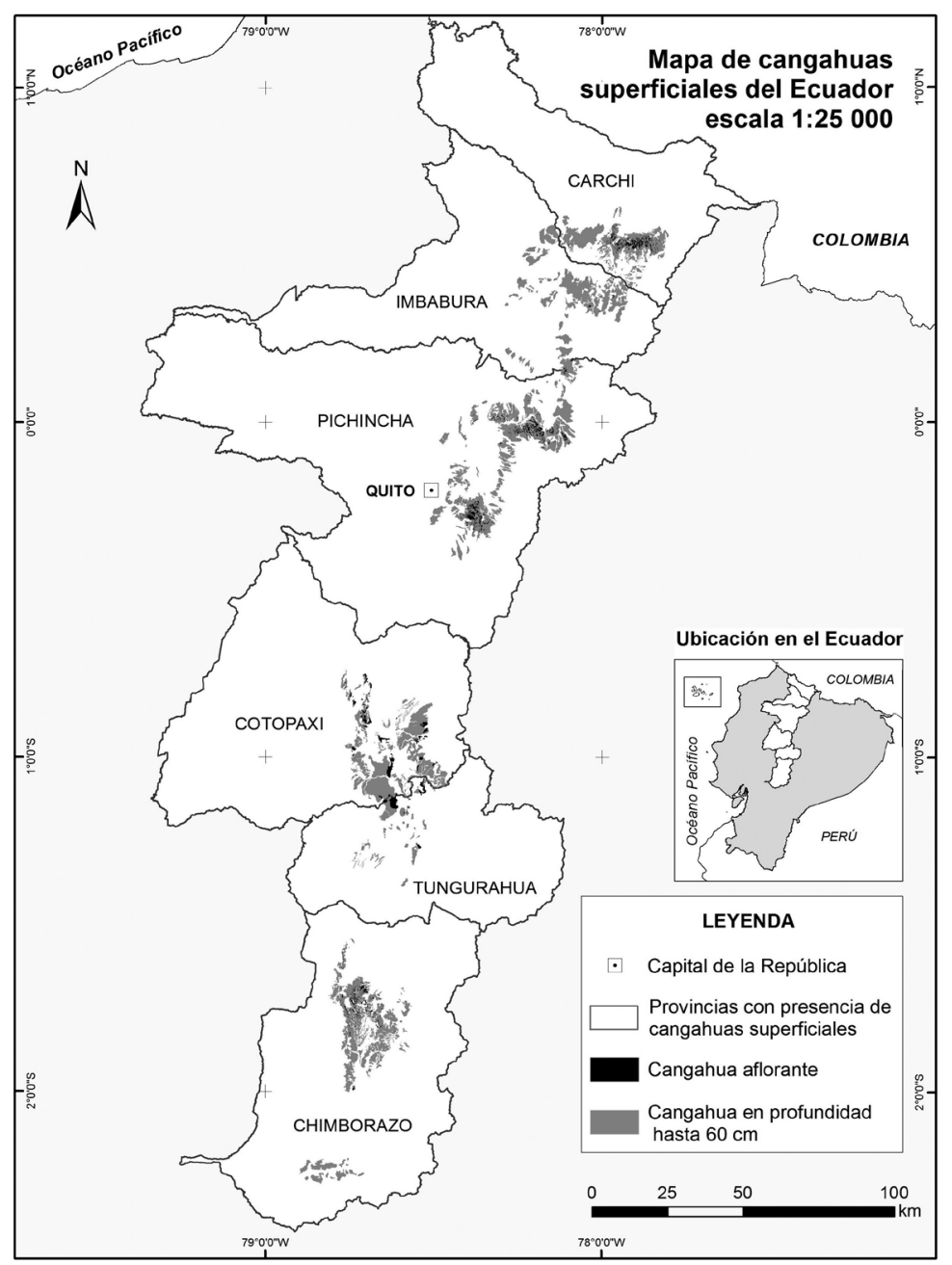

Figura 7. Mapa de cangahuas superficiales del Ecuador a escala 1:25 000. 
La Tabla 1 y la Figura 8 presentan el área de las cangahuas superficiales. El área total es de 181.487 ha, de las cuales 13.162 ha corresponden a cangahua aflorante y 168.325 ha de cangahua en profundidad hasta $60 \mathrm{~cm}$.

Tabla 1. Área de cangahua aflorante y en profundidad de hasta $60 \mathrm{~cm}$ a nivel provincial en el Ecuador.

\begin{tabular}{lccc}
\hline \multicolumn{1}{c}{$\begin{array}{c}\text { Provincia } \\
\text { Cangahua aflorante } \\
\text { (ha) }\end{array}$} & $\begin{array}{c}\text { Cangahua en profundidad } \\
\text { hasta } \mathbf{6 0} \mathbf{~ c m} \text { (ha) }\end{array}$ & $\begin{array}{c}\text { Total provincial } \\
\text { (ha) }\end{array}$ \\
Carchi & 2.207 & 21.743 & 23.950 \\
Chimborazo & 1.807 & 34.721 & 36.528 \\
Cotopaxi & 3.659 & 32.655 & 36.314 \\
Imbabura & 152 & 26.985 & 27.137 \\
Pichincha & 3.795 & 46.130 & 49.925 \\
Tungurahua & 1.542 & 6.091 & 7.633 \\
Total Nacional & 13.162 & 168.325 & 181.487 \\
\hline
\end{tabular}

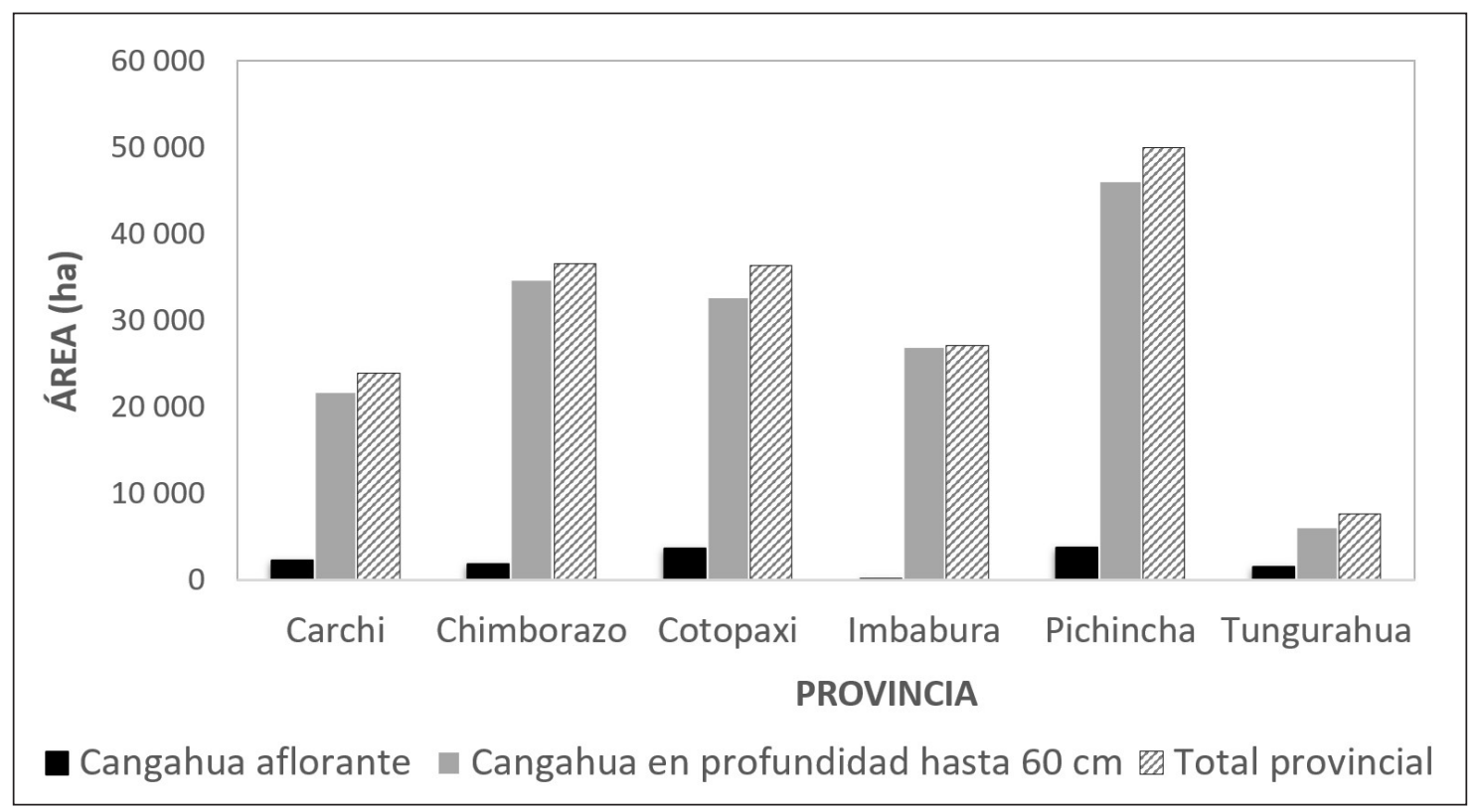

Figura 8. Histograma del área de cangahua aflorante y en profundidad de hasta $60 \mathrm{~cm}$ a nivel provincial en el Ecuador.

El análisis de los resultados obtenidos en el estudio a nivel provincial indica que la que mayor área, tanto de cangahua aflorante como de cangahua en profundidad, corresponde a Pichincha con 49.925 ha, seguida de Chimborazo con 36.528 ha y Cotopaxi con $36.314 \mathrm{ha}$, mientras que la menor área corresponde a Tungurahua con 7.623 ha. No fue posible compa- rar estos datos con los de los estudios realizados por MAG \& ORSTOM (1982) debido a que difieren en la metodología y escala de trabajo. De igual manera, no se puedo comparar con los estudios del IEE et al., (2015) y MAGAP (2016) dado que sus objetivos y metodologías se centraron en analizar a los suelos en general, más no a las cangahuas en específico. 
Tabla 2. Distribución de las cangahuas según la altitud.

\begin{tabular}{ccccc}
\hline $\begin{array}{c}\text { Rango de altitud } \\
(\mathbf{m})\end{array}$ & $\begin{array}{c}\text { Cangahua aflorante } \\
\text { (ha) }\end{array}$ & $\begin{array}{c}\text { Cangahua en profundidad } \\
\text { hasta } \mathbf{6 0} \mathbf{~ c m ~ ( h a ) ~}\end{array}$ & $\begin{array}{c}\text { Subtotal } \\
\text { (ha) }\end{array}$ & $\begin{array}{c}\text { Porcentaje } \\
\text { (\%) }\end{array}$ \\
$1.300-2.000$ & 44 & 4.353 & 4.397 & 3 \\
$2.000-3.200$ & 9.264 & 121.387 & 130.651 & 72 \\
$3.200-3.600$ & 3.739 & 40.248 & 43.987 & 24 \\
$3.600-4.000$ & 115 & 2.337 & 2.452 & 1 \\
Total & 13.162 & 168.325 & 181.487 & 100 \\
\hline
\end{tabular}

La Tabla 2 presenta los rangos de altitud de las áreas donde se encontraron las cangahuas con su respectiva superficie. La cangahua en profundidad se localizó de los 1.300 a $4.000 \mathrm{~m}$, mientras que la cangahua aflorante se encontró desde 1.470 a $3.650 \mathrm{~m}$. Del área total, el $2 \%$ (4.397 ha) se encuentra en zonas relativamente bajas que van desde 1.300 a $2.000 \mathrm{~m}$, el $72 \%$ (130.651 ha) se localiza en altitudes desde 2.000 a $3.200 \mathrm{~m}$ y solamente el $1 \%$ (2.452 ha) corresponde a las zonas más altas en el rango de 3.600 a $4.100 \mathrm{~m}$. La Figura 9 muestra el esquema de un corte transversal del callejón interandino ecuatoriano con la distribución de las cangahuas. Estos datos divergen de los del estudio realizado por Noní \& Viennot (1994) que localizaron a las cangahuas en áreas comprendidas entre 2.500 a $3.200 \mathrm{~m}$. Esta inconsistencia se debería principalmente a que los suelos de las zonas altas (> $3.200 \mathrm{~m}$ ) se están erosionando.

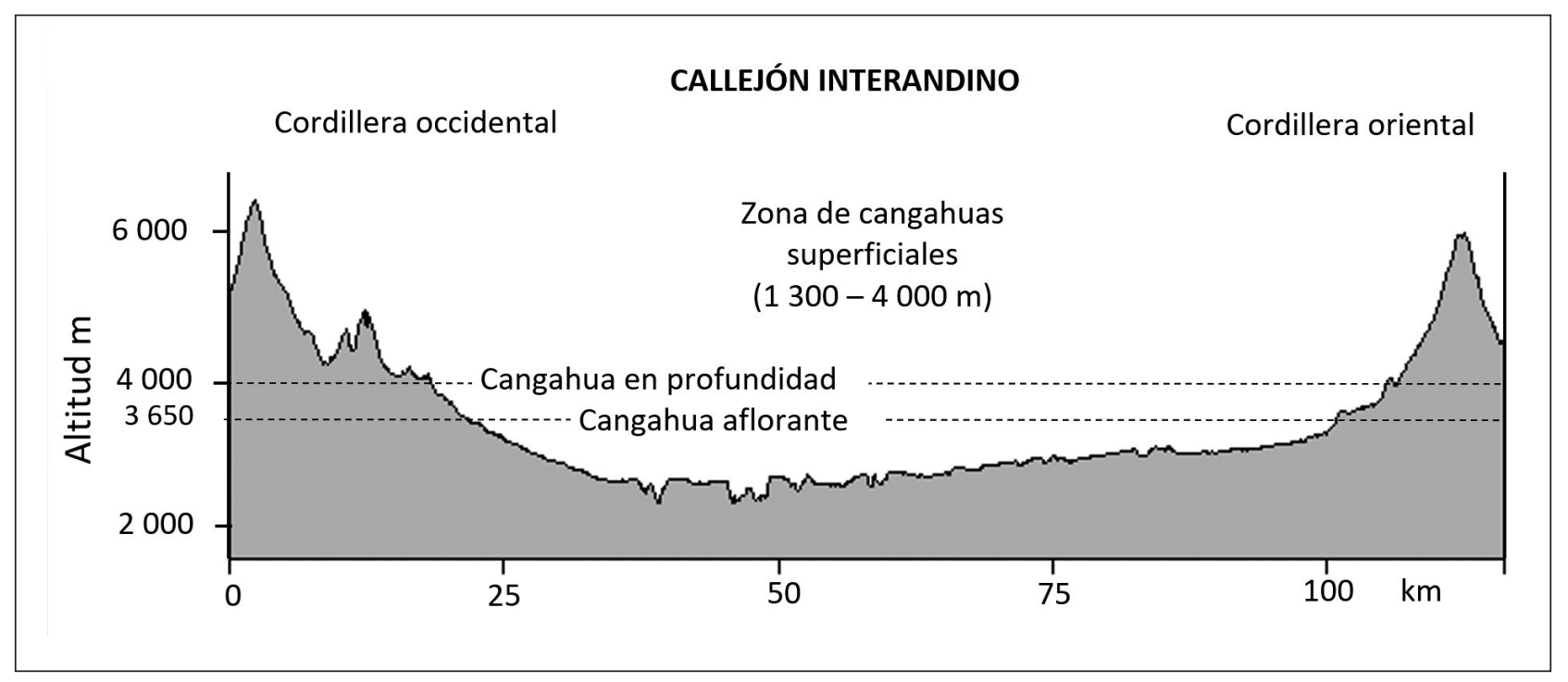

Figura 9. Distribución de las cangahuas respecto a la altitud en el perfil del callejón interandino ecuatoriano.

\section{Conclusiones}

La metodología utilizada en este estudio permitió establecer la dinámica del comportamiento y el patrón espacial de las cangahuas. Se identificaron los afloramientos de cangahua y la presencia de este material en profundidad, lo que hizo posible medir su área e identificar eficientemente los suelos degra- dados que han llegado a cangahua en la Sierra ecuatoriana. A nivel nacional, el área total de cangahuas superficiales ubicadas a profundidades de 0 a $60 \mathrm{~cm}$ es de 181.486 ha, de las cuales 13.161 ha corresponden a cangahua aflorante y 168.324 ha a cangahua en profundidad, distribuidas en las provincias de Carchi, Chimborazo, Cotopaxi, Imbabura, Pichincha y Tungurahua. A nivel provincial, la mayor superfi- 
cie total de cangahuas superficiales, tanto aflorante como en profundidad, corresponde a Pichincha con 49.925 ha, seguida de Chimborazo con 36.528 ha, la menor superficie corresponde a Tungurahua con 7.632 ha. Además, se demostró que las cangahuas se localizan entre los 1.300 a $4.000 \mathrm{~m}$ de altitud. El mapa es apto para análisis a nivel nacional, provincial y cantonal y constituye una línea base para la toma de decisiones. El mapa se encuentra disponible en formato vector en el Geoportal del Ministerio de Agricultura y Ganadería en http://geoportal.agricultura.gob.ec/.

\section{Agradecimientos}

Este estudio es parte del proyecto "Rehabilitación sostenible de suelos con cangahua como mecanismo de resiliencia frente al cambio climático" llevado a cabo por el equipo de suelos de la Direc-

\section{Referencias}

ArcGIS Earth 1.5 (2017). Provincias: Carchi, Imbabura, Pichincha, Cotopaxi, Tungurahua $y$ Chimborazo. Coordenadas $78^{\circ} 00^{\prime} 00^{\prime \prime} \mathrm{W}$ $0^{\circ} 40^{\prime} 00^{\prime \prime} \mathrm{N}$ y $78^{\circ} 50^{\prime} 00^{\prime \prime} \mathrm{W} 2^{\circ} 20^{\prime} 00^{\prime \prime} \mathrm{S}$. Elevación Indeterminada, Escala Indeterminada. Fecha de Imágenes Indeterminada. Fuente de imágenes: ESRI, DigitalGlobe, GeoEye, Earthstar Geographics, CNES/Airbus DS, USDA, USGS, AeroGRID, IGN, and the GIS User Community.

Báez, A., Ascencio, E., Prat, C., \& Márquez, A. (1997). Análisis del comportamiento de cultivos en tepetate $\mathrm{t} 3$ incorporado a la agricultura de temporal, Texoco (México). En: Zebrowski, C., Quantin, P., \& Trujillo, G. (eds.) Suelos volcánicos endurecidos, III Simposio Internacional (pp. 128-137). Quito, Ecuador: Unión Europea; Office de la Recherche Scientifique et Technique Outre-Mer.,Pontificia Universidad Católica del Ecuador; Universidad Central del Ecuador.

Bernard, B., \& Andrade, D. (2011). Volcanes Cuaternarios del Ecuador Continental. Poster Informativo. Instituto Geofísico de la Escuela Politécnica Nacional \& Institut de Recherche pour le Développement (Francia). Quito, Ecuador. Disponible en URL: http://www.igepn.edu.ec/ ción de Investigación y Generación de Datos Multisectoriales (DIGDM) de la Coordinación General del Sistema de Información Nacional (CGSIN) del Ministerio de Agricultura y Ganadería (MAG). El levantamiento de puntos de campo se concluyó gracias al valioso apoyo de los técnicos de las Unidades Zonales de Información (UZI) y de las Direcciones Provinciales Agropecuarias de Carchi, Imbabura; Pichincha, Cotopaxi, Tungurahua y Chimborazo del MAG. Nuestro agradecimiento a Roberto Guerrero y Catalina Jiménez, miembros del equipo técnico del Gobierno Autónomo Descentralizado del Cantón Pedro Moncayo, por apoyarnos con los vehículos para el levantamiento de información en campo. Agradecemos también a Víctor Bucheli ex-Coordinador de la CGSIN y Santiago González ex-Director de la DIGDM, por el apoyo durante su administración y a Gustavo Tapia por la revisión técnica que enriqueció el contenido del documento.

publicaciones-para-la-comunidad/14155-volcanes-cuaternarios-del-ecuador-continental [Consulta 03 marzo del 2016]

Cangás, J., \& Trujillo, G. (1997). Experiencia de recuperación de cangahua en la provincia de Carchi (Ecuador). En: Zebrowski, C., Quantin, P., \& Trujillo, G. (eds.) Suelos volcánicos endurecidos, III Simposio Internacional (pp. 501505). Quito, Ecuador: Unión Europea; Office de la Recherche Scientifique et Technique Outre-Mer, Pontificia Universidad Católica del Ecuador; Universidad Central del Ecuador.

Navarro, E., Poupon, H., \& Pérez, M. (eds.) (1998). Aptitud productiva en suelos volcánicos endurecidos (Tepetates). Montecillo, México: Colegio de Postgraduados, Office de la Recherche Scientifique et Technique Outre-Mer.

De Noní, G., \& Viennot, M. (1994). Les recherches sur l'érosion par l'ORSTOM, évolution et perspectives: cas de la montagne équatorienne - Les écosystèmes intertropicaux, Fonctionnement et Usages. Lyon: Ecole Normale Supérieure, 13, 14 et 15 janvier 1993.

De Noní, G., Trujillo, G., Viennot, M., \& Custode, E. (1997). Ruissellement et érosion sur des par- 
celles de cangahua réhabilitée (période 19941996). En: Zebrowski, C., Quantin, P., \& Trujillo, G. (eds.) Suelos volcánicos endurecidos, III Simposio Internacional (pp. 331-342). Quito, Ecuador: Unión Europea; Office de la Recherche Scientifique et Technique Outre-Mer, Pontificia Universidad Católica del Ecuador; Universidad Central del Ecuador.

Etchevers, J., López, R., Zebrowski, C., \& Peña, D. (1992). Características químicas de tepetates de referencia de los Estados de México y de Tlaxcala, México. Terra, 10 (Número especial), 171-177.

González, A., \& Ringleb, R. (1992). Características espectrales de la cangahua expuesta en el Ecuador. Terra, 10 (Número especial), 120-130.

Google Earth Pro 7.3 (2017). Provincias: Carchi, Imbabura, Pichincha, Cotopaxi, Tungurahua $y$ Chimborazo. Coordenadas $78^{\circ} 00^{\prime} 00^{\prime} \mathrm{W}$ $0^{\circ} 40^{\prime} 00^{\prime \prime} \mathrm{N}$ y $78^{\circ} 50^{\prime} 00^{\prime \prime} \mathrm{W} 2^{\circ} 20^{\prime} 00^{\prime}$ 'S. Elevación Indeterminada, Escala Indeterminada. Fecha de Imágenes: 01/2001 hasta 09/2017. Fuente de imágenes: Lansat, Copernicus, CNES/Airbus, DigitalGlobe, US Dept of State Geographer, Data SIO, NOAA, U.S. Navy, NGA, GEBCO.

IEE, MAGAP \& SENPLADES (2015). Información de geopedología del proyecto Generación de Geoinformación para la Gestión del Territorio a Nivel Nacional escala 1:25 000. Quito, Ecuador: Instituto Espacial Ecuatoriano; Ministerio de Agricultura, Ganadería, Acuacultura y Pesca; y Secretaría Nacional de Planificación y Desarrollo.

IGM (2008). Modelo digital del terreno con resolución horizontal de $30 \mathrm{~m}$. Quito, Ecuador: Instituto Geográfico Militar.

Jiménez, W., Montúfar, C., \& Prat, C. (2016). Cartografía de suelos con cangahuas mediante teledetección en los cantones de Cayambe, Pedro Moncayo y Pimampiro, Sierra Norte de Ecuador. En: Memorias del XXI Congreso Latinoamericano de la Ciencia del Suelo y XV Congreso Ecuatoriano de la Ciencia del Suelo. Quito, Ecuador: Sociedad Ecuatoriana de la Ciencia del Suelo y Sociedad Latinoamericana de la Ciencia del Suelo. (Pendiente de publicación).

MAE (2015). Mapa del Sistema Nacional de Áreas Protegidas. Formato vector. Quito, Ecuador: Ministerio del Ambiente.
MAG \& ORSTOM (1982). Mapas y leyendas de suelos de la Sierra ecuatoriana a escala 1:50 000. Quito, Ecuador: Ministerio de Agricultura y Ganadería mediante el Programa Nacional de Regionalización y Office de la Recherche Scientifique et Technique Outre-Mer (Francia).

MAGAP (2013). Ortofotografia del Ecuador de los años 2005 a 2006 y 2008 a 2013, con resolución espacial entre 30 y $50 \mathrm{~cm}^{2}$. Quito, Ecuador: Ministerio de Agricultura, Ganadería, Acuacultura y Pesca.

MAGAP (2016). Información de geopedología del proyecto "Levantamiento de Cartografia $\mathrm{Te}$ mática escala 1:25 000, lote 1 y 2”. Quito, Ecuador: Ministerio de Agricultura, Ganadería, Acuacultura y Pesca.

Metzler, E., Jiménez, W., \& Loayza, V. (2016). Cartografía de suelos con cangahuas superficiales en la parroquia Tocachi, Ecuador, a escala 1:15 000. En: Memorias del XXI Congreso Latinoamericano de la Ciencia del Suelo y XV Congreso Ecuatoriano de la Ciencia del Suelo. Quito, Ecuador: Sociedad Ecuatoriana de la Ciencia del Suelo y Sociedad Latinoamericana de la Ciencia del Suelo. (Pendiente de publicación).

Navarro, H., \& Muñoz, S. (1997). Uso de recursos, rentabilidad y sustentabilidad en los sistemas económicos familiares. En: Zebrowski, C., Quantin, P., \& Trujillo, G. (eds.) Suelos volcánicos endurecidos, III Simposio Internacional (pp. 492-500). Quito, Ecuador: Unión Europea; Office de la Recherche Scientifique et Technique Outre-Mer.,Pontificia Universidad Católica del Ecuador; Universidad Central del Ecuador.

Nimlos, T. (1987). Nomenclatura de horizontes endurecidos en suelos de cenizas volcánicas. En: Ruiz, F. (ed) Uso y manejo de los tepetates para el desarrollo rural. Chapingo, México: UACh.

Nimlos, T., \& Zamora, C. (1992). Indurated volcanic ash soils in Peru. Terra, 10 (Número especial), 283-289.

Peña, D., \& Zebrowski, C. (1992). Caracterización física y mineralógica de los tepetates de la vertiente occidental de la Sierra Nevada. Terra, 10 (Número especial), 156-163. 
Pérez, M., \& García, M. (2013). Aplicaciones de la teledetección en degradación de suelos. Boletín de la Asociación de Geógrafos Españoles, 61, 285-308.

Podwojewski, P., Janeau, J., \& Leroux, Y. (2008). Effects of agricultural practices on the hydrodynamic of a deep tilled hardened volcanic-ash soil (cangahua) in Ecuador. Catena, 72, 179-190.

Prat, C. (1991). Etude du talpetate, horizon volcanique induré de la región Centre-Pacifique du Nicaragua. Genèse, caracterisation morphologique, phisico-chimique et hydro-dinamique, son rôle dans l'érosion des sols. Thèse de Doctorat, Université Paris.

Prat, C., Ordaz, V., \& Rugama, J. (2003). Impacto de la roturación y del manejo agronómico de un tepetate sobre su estructura. TERRA Latinoamericana, 21(1), 109-115.

Servenay, A. (1995). Spatialisation de la cangahua en Équateur à partir de données Spot: cas du bassin de Quito. Paris: Mémoire de maîtrise IUP Gestion de l'environnement, Université Paris VII, ORSTOM.

Servenay, A., \& Prat, C. (2000). Classification from Landsat TM of indurated volcanic materials (Tepetates) of the Mexican Neo-Volcanic Belt. In: Geocarto International 15 (pp 55-62).

Terán, G. (1997). La recuperación de suelos cangahuosos en el proyecto Licto. En: Zebrowski, C., Quantin, P., \& Trujillo, G. (eds.) Suelos volcánicos endurecidos, III Simposio Internacional (pp. 506-510). Quito, Ecuador: Unión Europea; Office de la Recherche Scientifique et Technique Outre-Mer.,Pontificia Universidad Católica del Ecuador; Universidad Central del Ecuador.
Trujillo, G., \& Arias, J. (1997). Productividad en cangahua rehabilitada, ensayos agronómicos. En: Zebrowski, C., Quantin, P., \& Trujillo, G. (eds.) Suelos volcánicos endurecidos, III Simposio Internacional (pp. 260-270). Quito, Ecuador: Unión Europea; Office de la Recherche Scientifique et Technique Outre-Mer.,Pontificia Universidad Católica del Ecuador; Universidad Central del Ecuador.

Vera, R., \& López, R. (1992). Tipología de la cangahua. Terra, 10 (Número especial), 113-119.

Zebrowski, C., Peña, D., \& Valencia, J. (1989). Reincorporación de los tepetates a la producción agrícola. II. Avances de los trabajos de clasificación y cartografía. En: Memorias de del XXII Congreso Nacional de la Ciencia del Suelo. Chapingo, México: Sociedad Mexicana de la Ciencia del Suelo.

Zebrowski, C. (1997). Los suelos volcánicos endurecidos en América Latina. En: Zebrowski, C., Quantin, P., \& Trujillo, G. (eds.) Suelos volcánicos endurecidos, III Simposio Internacional (pp. 15-23). Quito, Ecuador: Unión Europea; Office de la Recherche Scientifique et Technique Outre-Mer, Pontificia Universidad Católica del Ecuador; Universidad Central del Ecuador.

Zebrowski, C., \& Sánchez, B. (1997). Los costos de rehabilitación de los suelos volcánicos endurecidos. En: Zebrowski, C., Quantin, P., \& Truji1lo, G. (eds.) Suelos volcánicos endurecidos, III Simposio Internacional (pp. 462-471). Quito, Ecuador: Unión Europea; Office de la Recherche Scientifique et Technique Outre-Mer.,Pontificia Universidad Católica del Ecuador; Universidad Central del Ecuador. 